\title{
Strategies Towards Synthesis of Advanced Functional Sorbents Performance for Uranium Uptake from Seawater
}

Sadananda Das, ${ }^{\dagger, *}$ Zongyu Wang, ${ }^{\dagger *}$ Suree Brown, ${ }^{\dagger}$ Christopher J. Janke, ${ }^{\dagger}$ Richard T. Mayes,${ }^{\dagger}$ Gary A. Gill, ${ }^{\perp}$ and Sheng Dai ${ }^{\dagger, *}, *$

${ }^{\dagger}$ Chemical Sciences Division, Oak Ridge National Laboratory, Oak Ridge, Tennessee 37831, United States

\#. Department of Chemistry, The University of Tennessee, Knoxville, Tennessee 37996, United States

${ }^{\perp}$ Marine Sciences Laboratory, Pacific Northwest National Laboratory, Sequim, Washington 98382, United States

\section{Corresponding Author}

*E-mail: amisdas@gmail.com

*E-mail:wangz@ornl.gov

*E-mail: dais@ ornl.gov 


\section{Materials and Methods}

\section{Materials}

All chemicals were reagent grade or higher. Acrylonitrile (AN), itaconic acid (ITA), tetrahydrofuran (THF), methanol, dimethylsulfoxide (DMSO), dimethylformamide (DMF), isopropanol (IPA), hydroxylamine hydrochloride (HA-HCl), and potassium

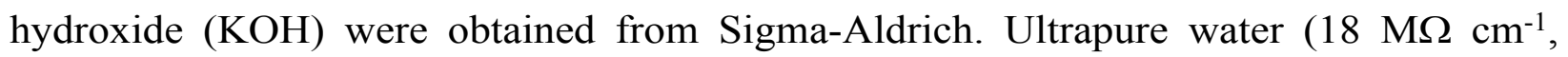
Thermo scientific Nanopore) was used in the preparation of $\mathrm{HA}-\mathrm{HCl}$ and $\mathrm{KOH}$ solutions. High-surface-area polyethylene fibers (PE, hollow-gear) were prepared by bi-component melt-spinning at Hills, Inc. (Melbourne, FL, USA), using polylactic acid (PLA) as the coextrusion polymer. Reagents used to prepare the screening brine solution include uranyl nitrate hexahydrate $\left(\mathrm{UO}_{2}\left(\mathrm{NO}_{3}\right)_{2} \cdot 6 \mathrm{H}_{2} \mathrm{O}, \mathrm{B} \& \mathrm{~A}\right.$ Quality), sodium bicarbonate $\left(\mathrm{NaHCO}_{3}, \mathrm{ACS}\right.$ Reagent, Aldrich), and sodium chloride (>99\%, Aldrich). A 1000 ppm uranium (U) standard solution (High Purity Standards, North Charleston, USA) was used to prepare the Inductively Coupled Plasma (ICP) standards.

\section{Preparation of Adsorbent}

\section{Radiation-induced Graft Polymerization (RIGP)}

The adsorbent fibers were prepared by RIGP at the NEO Beam Electron Beam Crosslinking Facility (Mercury Plastics, Middlefield, OH, USA). Before irradiation, the coextruded PLA was removed from the fibers by refluxing with excess THF at $65-70{ }^{\circ} \mathrm{C}$, followed by drying at $40{ }^{\circ} \mathrm{C}$ under vacuum. The pre-weighed dry fiber samples, sealed inside double-layered plastic bags under nitrogen within a nitrogen atmosphere glove bag, were irradiated to a dose of $200 \pm 10 \mathrm{kGy}$ using 4.1 MeV electrons and $1.25 \mathrm{~mA}$ current from an RDI Dynamitron electron beam machine. The irradiated fibers were transferred to a nitrogen glove bag and immersed in a $300 \mathrm{~mL}$ flask containing previously degassed grafting solutions consisting of AN and ITA in DMSO and placed in an oven at $64{ }^{\circ} \mathrm{C}$ for grafting for 18 hours. The grafted fibers were washed with DMF to remove unreacted monomers and homopolymers followed by rinsing with methanol and dried at $40{ }^{\circ} \mathrm{C}$ under vacuum. 
The PAN grafted PE fibers (AF1 hereafter) were treated with 10 wt \% hydroxylamine hydrochloride, following neutralized with $\mathrm{KOH}$, for conversion into amidoxime (AO) groups. The hydroxylamine solution was prepared using a variety of solvents: deionized water, methanol, IPA, DMSO, 50/50 (w/w) water-methanol, 50/50 $(\mathrm{w} / \mathrm{w})$ water-IPA, 20/80 (w/w) water-THF, 50/50 (w/w) water-THF, and 50/50 (w/w) water-DMSO. The amidoximation of AF1 with different hydroxylamine solutions was carried out at different temperatures (i.e., $60,65,70,75$, and $80^{\circ} \mathrm{C}$ ) and for different periods (i.e. 1, 3, 6, $24 \mathrm{~h}$ ). The samples were then washed with deionized water followed by drying at $40{ }^{\circ} \mathrm{C}$ under vacuum.

Scheme S1. An illustration of the conversion of grafted polyacrylonitrile into open chain amidoxime and cyclic imide dioxime upon treatment with hydroxylamine with heat.<smiles>CCC(C#N)CC(C#N)CC(C#N)CC(CC)(CC(=O)O)CC(C#N)CC(C)C</smiles>

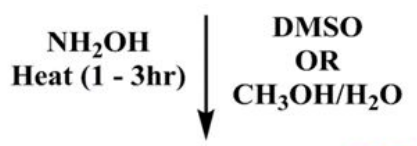<smiles>CCCC(CC(C)CC(CC(CC(=O)O)(CC(CC(C)C)/C(N)=N\O)/C(N)=N\O)C(=O)O)/C(N)=N/O</smiles><smiles>CCC1CC(CC(CC(=O)O)(CC(CC2CC(CC)C(N)NC2=NO)C(N)=NO)C(=O)O)C(=O)NC1=NO</smiles>

KOH conditioning 
The amidoximated AF1adsorbents were conditioned with $0.44 \mathrm{M} \mathrm{KOH}$ at $80^{\circ} \mathrm{C}$ for 1 hour before exposure to the screening brine solution screening solution as well as filtered seawater for determining the uranium uptake capacity.

\section{Characterization Methods}

The SEM images were collected using a JOEL, JSM-6060 SEM at $4 \mathrm{kV}$. The Fourier Transform Infrared (FTIR) spectra of the AF1 samples were recorded on a Perkin Elmer Frontier FTIR with a single bounce diamond attenuated total reflectance (ATR) accessory at $2 \mathrm{~cm}^{-1}$ resolution and averaged over 16 scans. All ${ }^{13} \mathrm{C}$ and ${ }^{1} \mathrm{H}$ NMR experiments reported in this study were carried out on a Bruker Avance $400 \mathrm{MHz}$ NMR spectrometer.

Batch screening experiments with high uranium concentration brine were conducted to identify potential candidates for seawater contact. The sodium-based brine solution used for screening consists of $193 \mathrm{ppm}$ sodium bicarbonate, $25,600 \mathrm{ppm}$ sodium chloride, and 8 ppm uranium from uranyl nitrate hexahydrate in $18.2 \mathrm{M} \Omega \mathrm{cm}^{-1}$ water. The $\mathrm{pH}$ of the test solution was approximately 8 . The concentrations of sodium, chloride and bicarbonate ions are representative of seawater. A sample of the solution was collected before and after the addition of adsorbent to determine the initial and final uranium concentrations. Each of the $\mathrm{KOH}$-conditioned AF1 samples ( $15 \mathrm{mg}$ ) was then contacted with $750 \mathrm{~mL}$ of uranyl brine solution for 24 hours at room temperature with constant shaking ( $400 \mathrm{rpm})$. The initial and final solutions were analyzed using inductively coupled plasma-optical emission spectroscopy (Perkin Elmer Optima 2100DV ICP-OES). The uranium adsorption capacity ( $\mathrm{g}-\mathrm{U} / \mathrm{Kg}$-adsorbent) was determined from the difference in uranium concentration in the initial and final solutions and the volume of the uranyl brine, using the following equation:

$$
\text { Capacity }=\left[\frac{\text { Initial }[U]\left(\frac{n g}{L}\right)-\text { Final }[U]\left(\frac{m g}{L}\right)}{\text { gof dry adsorbent }}\right] \times \text { Soln. vol. (L) } \quad \text { Eq. S1 }
$$

A linear calibration curve was obtained using six standard uranium solutions, with concentrations ranging from $0-10 \mathrm{ppm}$. These standards were prepared from a $1000 \mathrm{ppm}$ uranium stock solution in $5 \mathrm{wt} \%$ nitric acid. A blank solution of $2-3 \mathrm{wt} \%$ nitric acid was also prepared and washouts were monitored between samples to ensure no uranium was carried over into the next analysis. In addition, a solution of $5 \mathrm{ppm}$ yttrium in $2 \mathrm{wt} \%$ nitric 
acid was used as an internal standard to correct for drops in signal intensity with complex matrix samples. The internal standards were prepared from a $1000 \mathrm{ppm}$ stock solution (High-Purity Standards, North Charleston, USA).

\section{Natural Seawater Adsorption Tests}

Determination of the adsorption capacity and adsorption kinetics of the AF1 adsorbents in natural seawater was carried out at the Marine Sciences Laboratory, Pacific Northwest National Laboratory (PNNL) in Sequim, Washington, USA for 56 days in flowthrough columns using filtered seawater. The quality of seawater was periodically monitored for $\mathrm{pH}$, temperature, salinity, and trace-metal concentrations over the exposure period. A schematic diagram of the flow-through-column test has been previously reported. ${ }^{1}$ Marine testing was performed using filtered $(0.45 \mu \mathrm{m})$ seawater at a temperature of $20 \pm 2{ }^{\circ} \mathrm{C}$ and a flow rate of $250 \mathrm{~mL} / \mathrm{min}$, using an actively pumped system. Glass wool and glass beads were used as packing materials in the columns to secure the adsorbent.

The AF1 adsorbents ( $\sim 50 \mathrm{mg}$ each) were conditioned with $0.44 \mathrm{M} \mathrm{KOH}$ at $80^{\circ} \mathrm{C}$ for $1 \mathrm{~h}$. The conditioned adsorbents were packed into flow-through columns and were held in place with glass wool and $5 \mathrm{~mm}$ glass beads. Ambient seawater was pumped from Sequim Bay and successively filtered until achieving $0.45 \mu \mathrm{m}$ filtration for the continuous-flow adsorption experiment. Temperatures and flow rates were monitored at $10 \mathrm{~min}$ intervals using a temperature logger equipped with a flexible hermetically sealed RTD sensor probe (OMEGA Engineering, Stamford, CT, USA) and an in-line turbine-style flow sensor (Model DFS-2W, Digiflow Systems), respectively. The temperature of the incoming seawater was maintained at $20 \pm 1{ }^{\circ} \mathrm{C}$ and the flow rate of seawater in each column was controlled at 250-300 $\mathrm{mL} / \mathrm{min}$. During the flow-through adsorption experiments, seawater salinity and $\mathrm{pH}$ were monitored daily using a hand-held salinometer (Model 30, YSI) and $\mathrm{pH}$ meter (Orion 3 STAR, Thermo). After 56 days of exposure in seawater was completed, the adsorbents were removed from the columns, desalted by thoroughly rinsing with deionized water, dried using a heating block, and weighed. The adsorbents were digested with a $50 \%$ aqua regia solution at $85{ }^{\circ} \mathrm{C}$ for 3 hours. Analysis of uranium and other trace elements in the digested solutions was carried out using a Perkin-Elmer Optima 5300DV 
ICP-OES, with quantification based on standard calibration curves. All adsorption capacity results were normalized to a salinity of 35 .
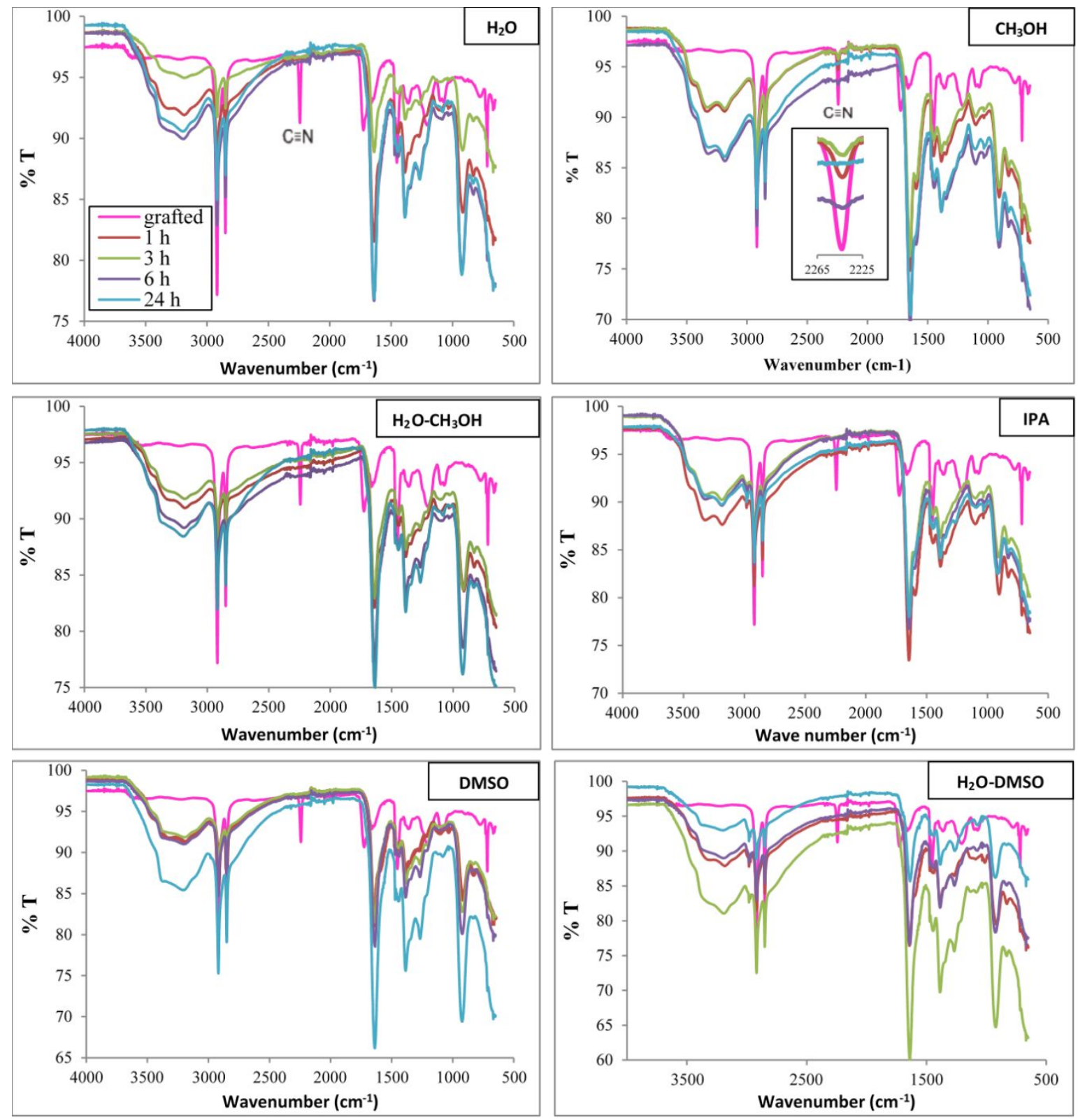

Figure S1. FTIR spectra of AF1 adsorbents amidoximated with $10 \mathrm{wt} \%$ hydroxylamine for 1, 3, 6, and $24 \mathrm{~h}$ at $80{ }^{\circ} \mathrm{C}$ in different solutions: $\mathrm{H}_{2} \mathrm{O}, \mathrm{CH}_{3} \mathrm{OH}, 50: 50$ (w/w) $\mathrm{H}_{2} \mathrm{O}-\mathrm{CH}_{3} \mathrm{OH}$, IPA, DMSO and 50:50 (w/w) $\mathrm{H}_{2} \mathrm{O}-\mathrm{DMSO}$. 


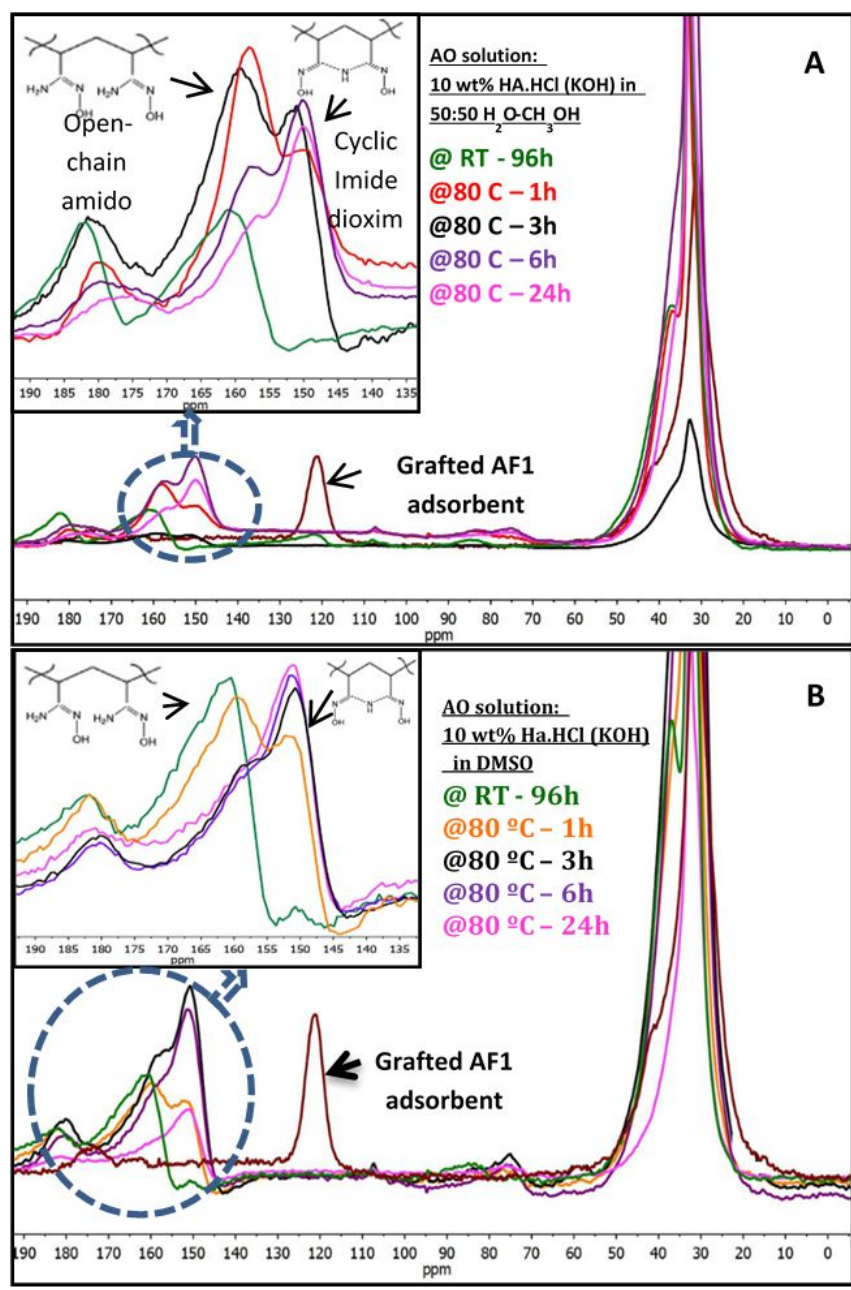

Figure S2. ${ }^{13} \mathrm{C} \mathrm{CP} / \mathrm{MAS}$ spectra of grafted $\mathrm{AF} 1$ and $\mathrm{AF} 1$ amidoximated with $10 \mathrm{wt} \%$ hydroxylamine at room temperature (for $96 \mathrm{~h}$ ) and $80^{\circ} \mathrm{C}$ (for 1, 3, 6 and $24 \mathrm{~h}$ ) in (A) 50:50 (w/w) $\mathrm{H}_{2} \mathrm{O}-\mathrm{CH}_{3} \mathrm{OH}$, (B) DMSO. 


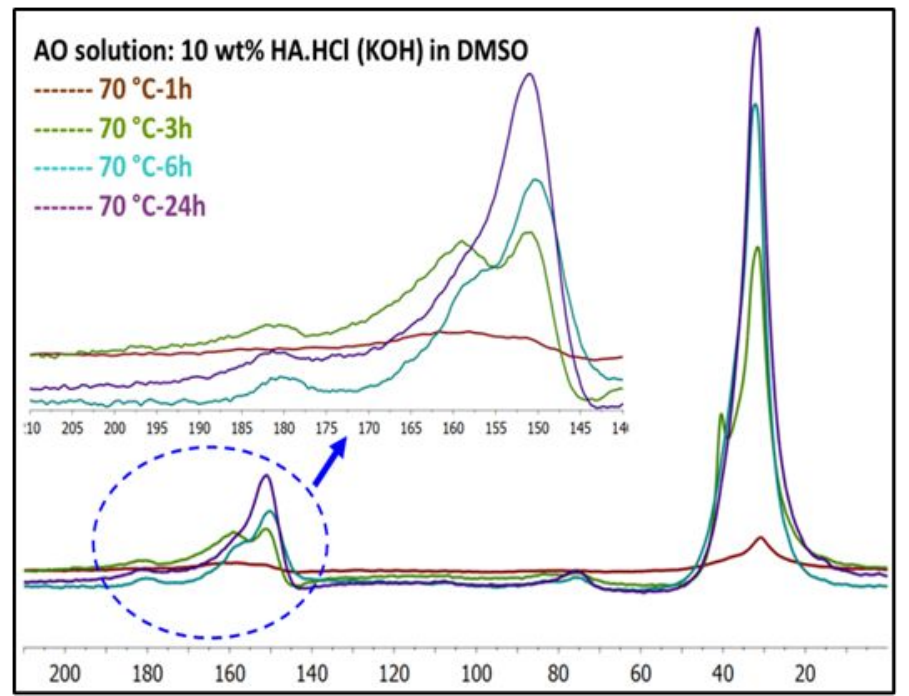

Figure S3. ${ }^{13} \mathrm{C} \mathrm{CP} / \mathrm{MAS}$ spectra of grafted PAN and amidoximated PAN fiber with 10 wt $\%$ hydroxylamine hydrochloride in DMSO at $70{ }^{\circ} \mathrm{C}$ for $3 \mathrm{~h}$
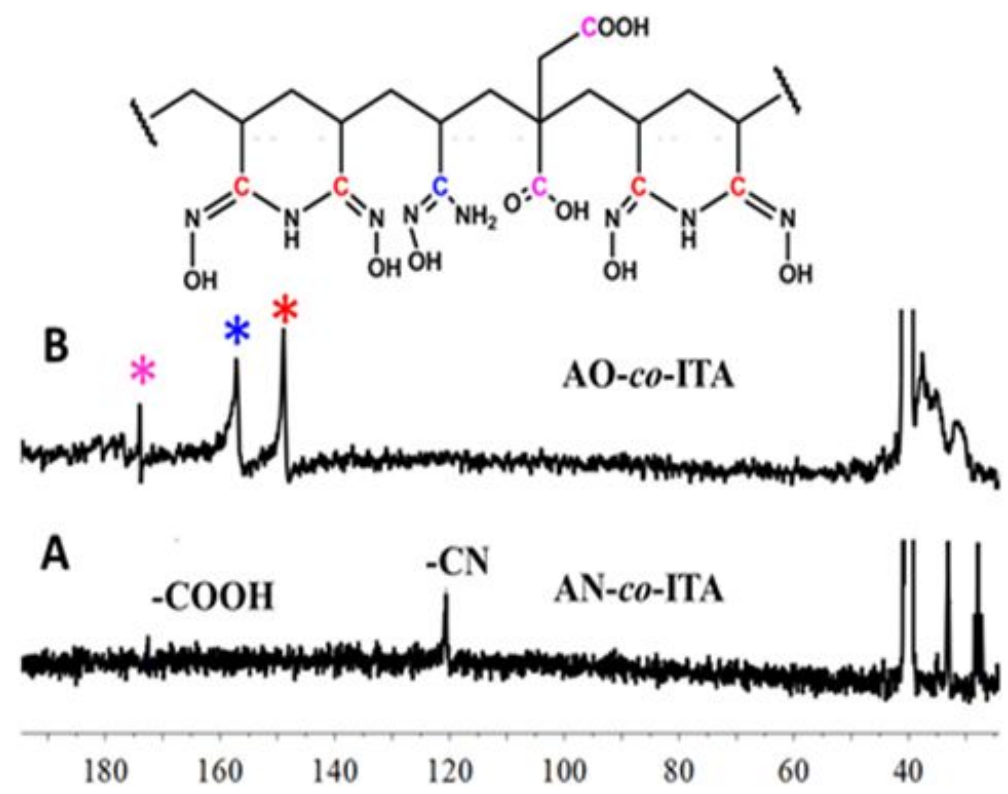

Figure S4. ${ }^{13} \mathrm{C}-\mathrm{NMR}$ spectra of (A) PAN-co-PITA polymer (DMSO- $d_{6}$ ) (B) PAN-co-PITA polymer treated with $\mathrm{NH}_{2} \mathrm{OH}\left(5 \%\right.$ in water + DMSO- $\left.d_{6}\right)$ at $70{ }^{\circ} \mathrm{C}, 3 \mathrm{~h}$.

\section{Reference}


(1) Das, S.; Brown, S.; Mayes, R. T.; Janke, C. J.; Tsouris, C.; Kuo, L. J.; Gill, G.; Dai, S. Novel poly(imide dioxime) sorbents: Development and testing for enhanced extraction of uranium from natural seawater. Chemical Engineering Journal 2016, 298, 125-135. 